- Original Article

\title{
The Prevalence of Gallstone Disease Is Significantly Lower in Natives than in Migrants of Jeju Island
}

\author{
Oh-Sung Kwonn ${ }^{1,+}$, Young-Kyu Kim ${ }^{2,+}$, Kyu Hee Her ${ }^{2, *}$ \\ 'Interdisciplinary Postgraduate Program in Biomedical Engineering, Jeju National University, Jeju, Korea \\ ${ }^{2}$ Department of Surgery, Jeju National University School of Medicine, Jeju, Korea
}

\begin{abstract}
Background: The eating habits of Jeju Island natives are quite different from those of the mainland people because of geographic isolation. Diet is a main factor affecting gallstone disease. We investigated the prevalence of gallstone disease in both Jeju Island natives and migrants and studied the risk factors affecting gallstone disease in the Jeju Island people.

Methods: A total of 20,763 subjects who underwent medical checkups at the Health Promotion Center of Jeju National University Hospital in Korea from January 2003 to December 2015 were enrolled in the study. Ultrasonography was used to determine the presence of gallbladder stones. Body mass index and biochemical parameters, including liver function test results, lipid profiles, and fasting blood glucose levels, were verified, and data on age, birthplace, and sex were collected from medical records. Univariate and multivariate analyses were performed to identify risk factors affecting gallstone disease.

Results: The prevalence of gallstone disease in the Jeju Island people was $4.0 \%$ : Jeju Island natives, $3.8 \%$ and migrants, 4.4\% ( $\mathrm{P}=0.047)$. After multivariate logistic regression analysis, the independent risk factors were older age, Jeju migrants, higher fasting blood glucose and alanine aminotransferase levels, and lower high-density lipoprotein cholesterol levels.

Conclusion: The prevalence of gallstone disease was significantly lower in natives than in migrants from Jeju Island. Older age, Jeju migrants, higher fasting blood glucose and alanine aminotransferase levels, and lower highdensity lipoprotein cholesterol levels contributed to gallstone disease prevalence in the Jeju Island people.
\end{abstract}

Keywords: Dietary Carbohydrates; Alcohol Drinking; Risk Factors; Gallstones

Received: January 12, 2018, Revised: April 2, 2018, Accepted: April 6, 2018

${ }^{*}$ Corresponding Author: Kyu Hee Her https://orcid.org/0000-0001-6576-1028

Tel: +82-64-717-1641, Fax: +82-64-717-1131, E-mail: herkh@jejunu.ac.kr

'These two authors contributed equally to this study. 


\section{INTRODUCTION}

By definition, gallstone disease (GD) refers to the presence of stones in the gallbladder or common bile duct. ${ }^{1)}$ Most patients with GD are asymptomatic and about $20 \%$ of GD patients become symptomatic during a 10-year period of follow-up. ${ }^{2)} \mathrm{GD}$ is frequently incidentally found during medical checkups through simple and relatively cost-effective abdominal ultrasound tests. ${ }^{3-5)}$ The prevalence of GD is reported to be $10 \%-20 \%$ in Western countries, and it is generally higher in women. Older subjects show a higher prevalence, for both sexes. It has been reported that the prevalence of GD reaches about $30 \%$ by the age of 70 years. $^{1,6)}$

Well-established risk factors of GD are age, sex, and obesity. Moreover, dietary habits, the number of pregnancies, the use of oral contraceptives, alcohol consumption, and smoking have been suggested as modifiable risk factors for GD. In particular, diet and chronic alcohol consumption have been reported as strong factors associated with the development of GD. ${ }^{7,8)}$

Jeju Island is the largest island located about 50 miles south from mainland Korea. Its natural environment and climate are different from the mainland. The soil layer in the island mainly contains basalt with high permeability. It is harmful for rice and wheat crops, but appropriate for cultivation of grains, such as millet, Sawa millet, and buckwheat. Jeju Island natives (JNs) mainly harvest and consume the latter crops. In addition, they consume more seafood than meat because of the characteristics of the island itself. Moreover, the proportion of high-risk alcohol drinkers is remarkably higher in the Jeju Island people than the mainland people. ${ }^{9}$ We hypothesized that such dietary habits and tendencies of heavy alcohol consumption could strongly affect the development of GD in JNs compared to Jeju Island migrants (JMs) because JNs lived longer on the Jeju Island as opposed to JMs. Thus, the aim of this study was to investigate whether the prevalence of GD diagnosed by ultrasonography differed between JNs and JMs by evaluation of their medical checkups and analyzing the risk factors for GD.

\section{METHODS}

\section{Subjects}

A total of 21,184 people visited the Health Promotion Center of Jeju National University Hospital for medical checkups from January 2003 to December 2015. Of these, 421 individuals who underwent gastrectomy or cholecystectomy or who were younger than 20 years of age were excluded. Subjects who underwent two or more medical checkups were considered as subjects irrespective of the total number of medical checkups, and their initial data were collected. Overall, 20,763 subjects were enrolled in the study. This study protocol was approved by the Institutional Review Board of Jeju National University Hospital (IRB approval no., JNUH 2015-12-006). Informed consent was confirmed by the board.

\section{Ultrasound Examination and Diagnosis}

Specialized radiologists performed abdominal ultrasound tests on all subjects using high-resolution ultrasound equipment IU22 (Koninklijke Philips Electronics NV, Amsterdam, The Netherlands). The abdominal regions were examined after the subjects had fasted for at least 8 hours. GD was identified based on the presence of echogenic and acoustic shadows and of the echo movement within the gallbladder depending on the position change. ${ }^{10)}$

\section{Data Collection and Definitions}

The height and weight of the subjects were measured. Venous blood samples were taken after fasting for 8 hours. The age and sex of the subjects were collected from their medical records. Their birthplace was identified using the social registration number in their medical records, and the subjects were divided into JNs and JMs. JNs were defined as individuals with social registration numbers identifying Jeju. JMs were defined as individuals who had other numbers.

Data relative to the subject's alcohol consumption were collected from the healthcare questionnaire, which was conducted from 2009 to 2015. For men, a high-risk alcohol drinker was defined as a subject consuming 7 or more glasses of alcohol (5 or more glasses in women) and drinking 2 or more times per week irrespective of the glass size. ${ }^{9)}$

Fasting blood glucose, aspartate aminotransferase (AST), alanine aminotransferase (ALT), alkaline phosphatase (ALP), gamma-glutamyl transferase $(\gamma$-GTP), total cholesterol, triglyceride, high-density lipoprotein cholesterol (HDL cholesterol), and low-density lipoprotein cholesterol (LDL cholesterol) were measured using venous blood samples taken after 8 hours of fasting.

The prevalence of GD was calculated according to sex, study year, and age. The subjects were divided into four groups according to age into $<50,50-59,60-69$, and $\geq 70$ age groups. Body mass index (BMI) was calculated by dividing weight by the square of height, and classifying it into four groups according to the World Health Organization's BMI for Asian populations classification: ${ }^{11)}$ low weight, $<18.5 \mathrm{~kg} / \mathrm{m}^{2}$; normal weight, $18.5-22.9 \mathrm{~kg} / \mathrm{m}^{2}$; overweight, $23.0-24.9 \mathrm{~kg} / \mathrm{m}^{2}$; and obese, $\geq 25.0 \mathrm{~kg} / \mathrm{m}^{2}$. Fasting blood glucose was classified into three groups based on the standard proposed by the American Diabetes Association in 2015: ${ }^{12)}$ normoglycemia, $<100 \mathrm{mg} / \mathrm{dL}$; impaired fasting glucose, 100-125 mg/dL; and diabetes, $\geq 126 \mathrm{mg} / \mathrm{dL}$. Fasting was defined as no caloric intake for at least 8 hours. Total cholesterol was classified into three groups: $<200 \mathrm{mg} / \mathrm{dL}, 200-239 \mathrm{mg} / \mathrm{dL}$, and $\geq 240$ $\mathrm{mg} / \mathrm{dL}$. The LDL cholesterol group was classified into five groups: $<100 \mathrm{mg} / \mathrm{dL}, 100-129 \mathrm{mg} / \mathrm{dL}, 130-159 \mathrm{mg} / \mathrm{dL}, 160-189 \mathrm{mg} / \mathrm{dL}$, and $\geq 190 \mathrm{mg} / \mathrm{dL}$. HDL cholesterol was classified into three groups: $<40$ $\mathrm{mg} / \mathrm{dL}, 40-60 \mathrm{mg} / \mathrm{dL}$, and $\geq 60 \mathrm{mg} / \mathrm{dL}$. Triglyceride levels were classified into four groups: $<150 \mathrm{mg} / \mathrm{dL}, 150-199 \mathrm{mg} / \mathrm{dL}, 200-499 \mathrm{mg} / \mathrm{dL}$, and $\geq 500 \mathrm{mg} / \mathrm{dL}$. Each lipid was classified according to the $2015 \mathrm{Kore}-$ an Guidelines for Management of Dyslipidemia. ${ }^{13)}$ AST levels were considered elevated if they were over $32 \mathrm{IU} / \mathrm{L}$ for men and over $26 \mathrm{IU} /$ $\mathrm{L}$ for women. ALT levels were considered elevated they were over 34 IU/L for men and over 24 IU/L for women. ${ }^{14)}$ ALP and $\gamma$-GTP levels 
were considered elevated if they were over $130 \mathrm{IU} / \mathrm{L}$ and $71 \mathrm{IU} / \mathrm{L}$, respectively.

\section{Statistical Analysis}

The clinical factors were compared using chi-square tests for categorical variables and Student t-tests for continuous variables according to the presence of GD. Binary logistic regression analysis and chi-square tests were performed to assess the risk factors for GD, including age, sex, birthplace, BMI, fasting blood glucose, total cholesterol, LDL cholesterol, HDL cholesterol, triglyceride, AST, ALT, $\gamma$-GTP, and ALP. A stepwise logistic regression was applied for the development of the fitted model estimating the predictive probability of GD when the factors were less than 0.1 on the univariate analysis by chi-square tests. A Pvalue of $<0.05$ was considered statistically significant. All statistical analyses were performed using PASW SPSS ver. 18.0 (SPSS Inc., Chicago, IL, USA).

\section{RESULTS}

\section{Sex, Age, and Annual Prevalence of Gallstone Disease}

Of the 20,763 subjects, 11,066 (53\%) were men and 9,697 (47\%) were women. The annual prevalence was lowest in 2003 (3.1\%) and highest in 2012 (5.0\%) (Figure 1), though the difference was not statistically significant $(\mathrm{P}=0.475)$.

GD was diagnosed in 821 subjects and the overall prevalence was 4.0\%: $4.1 \%(n=451)$ for men and 3.8\% $(n=370)$ for women. There was no significant difference in the prevalence of GD between both sexes $(\mathrm{P}=0.178)$ (Table 1). The prevalence of GD was $2.6 \%$ in the $<50$ age group, $3.7 \%$ in the $50-59$ age group, $5.6 \%$ in the $60-69$ age group, and $5.6 \%$ in the $\geq 70$ age group (Figure 2 ). There was a positive correlation between age and the prevalence of GD ( $r=0067, \mathrm{P}<0.001)$. With regard to age, JMs showed a significantly higher prevalence only in the 60-69year age group compared to JNs (Figure 2).

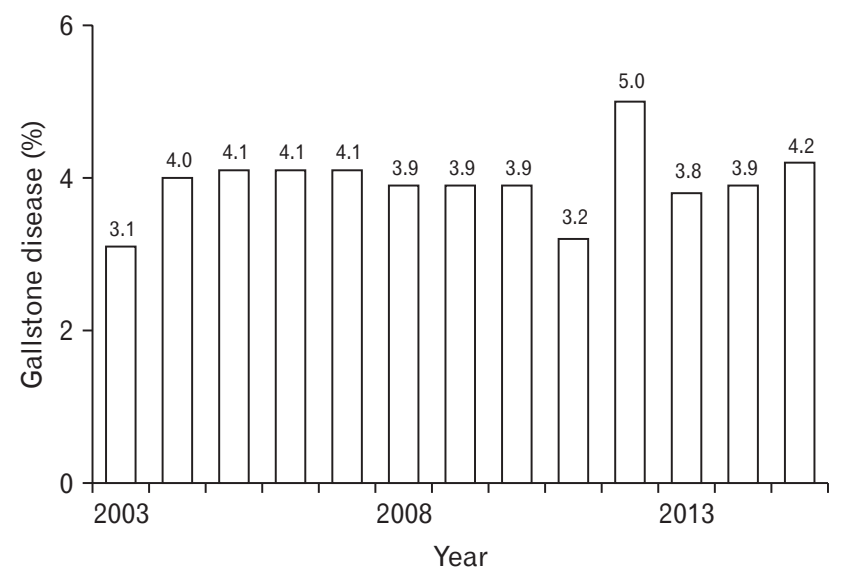

Figure 1. The annual prevalence of gallstone disease according to study years in the Jeju Island people who underwent medical checkups.

\section{Comparison of Clinical Variables between Subjects with and without Gallstone Disease}

The subjects were divided into two groups according to the presence or absence of GD. Mean age, BMI, and fasting blood glucose were significantly higher in subjects with GD. The prevalence of GD was significantly higher in JMs (4.4\%) than in JNs (3.8\%). The mean total cholesterol, LDL cholesterol, and triglyceride levels showed no significant difference between the two groups of subjects, but HDL cholesterol was significantly lower in subjects with GD. The mean AST, ALT, $\gamma$-GTP, and ALP were significantly higher in subjects with GD (Table 1).

Table 1. Comparison of the prevalence of GD according to the presence or absence of gallstones in Jeju Island people who underwent medical checkups

\begin{tabular}{|c|c|c|c|}
\hline Variable & $\begin{array}{l}\text { Subjects with } \\
G D(n=821)\end{array}$ & $\begin{array}{l}\text { Subjects without } \\
\text { GD }(n=19,942)\end{array}$ & P-value \\
\hline Sex & & & 0.178 \\
\hline Male & $451(4.1)$ & $10,615(95.9)$ & \\
\hline Female & 370 & $9,327(96.2)$ & \\
\hline Birthplace & & & 0.047 \\
\hline Jeju Island natives & $617(3.8)$ & $15,494(96.2)$ & \\
\hline Jeju Island migrants & 204( & 4,448 & \\
\hline Age (y) & $59.2 \pm 13.0$ & $54.5 \pm 13.5$ & $<0.001$ \\
\hline Body mass index $\left(\mathrm{kg} / \mathrm{m}^{2}\right)$ & $25.3 \pm 3.7$ & $24.5 \pm 3.3$ & $<0.001$ \\
\hline Fasting blood glucose (mg/dL) & $102.7 \pm 29.3$ & $97.6 \pm 29.3$ & $<0.001$ \\
\hline Total cholesterol (mg/dL) & $193.9 \pm 36.7$ & $196.3 \pm 37.2$ & 0.069 \\
\hline $\begin{array}{l}\text { Low-density lipoprotein cholesterol } \\
\text { (mg/dL) }\end{array}$ & $118.7 \pm 33.4$ & $118.7 \pm 33.7$ & 0.998 \\
\hline $\begin{array}{l}\text { High-density lipoprotein cholesterol } \\
(\mathrm{mg} / \mathrm{dL})\end{array}$ & $52.2 \pm 13.3$ & $54.5 \pm 13.6$ & $<0.001$ \\
\hline Triglyceride (mg/dL) & $118.2 \pm 75.7$ & $117.4 \pm 85.0$ & 0.795 \\
\hline Aspartate aminotransferase (IU/L) & $34.1 \pm 63.7$ & $27.9 \pm 29.4$ & $<0.001$ \\
\hline Alanine aminotransferase (IU/L) & $38.0 \pm 59.5$ & $30.6 \pm 40.7$ & $<0.001$ \\
\hline$\gamma$-glutamyl transferase (IU/L) & $55.7 \pm 80.4$ & $44.4 \pm 67.0$ & $<0.001$ \\
\hline Alkaline phosphatase (IU/L) & $151.6 \pm 70.0$ & $142.5 \pm 58.6$ & 0.002 \\
\hline
\end{tabular}

Values are presented as number (\%) or mean \pm standard deviation. $\mathrm{GD}$, gallstone disease.

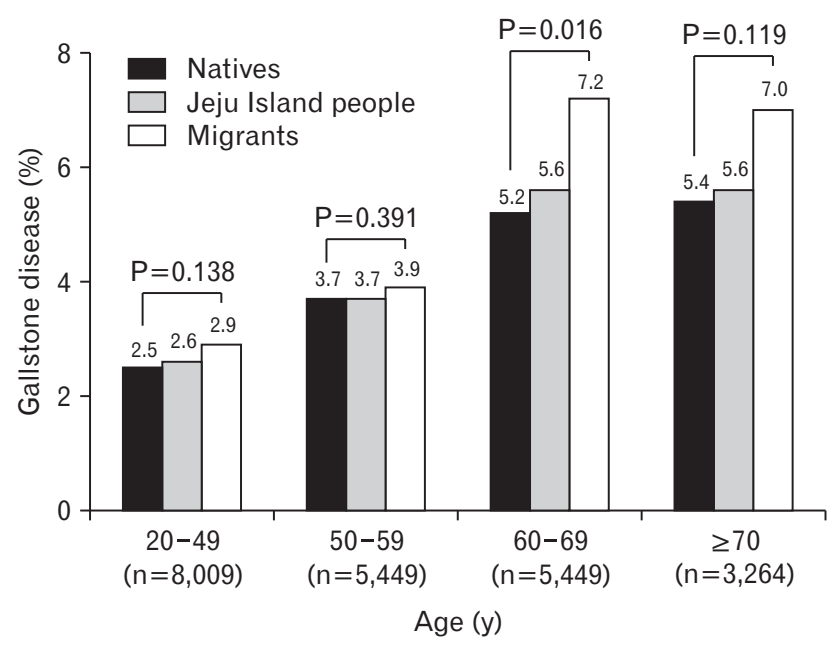

Figure 2. The prevalence of gallstone disease according to age groups in the Jeju Island people who underwent medical checkups. 
Table 2. Univariate analysis of the risk factors affecting gallstone disease in the Jeju Island people who underwent medical checkups

\begin{tabular}{|c|c|c|c|c|c|}
\hline Factors & No. of subjects & $\begin{array}{l}\text { No. with gallstone } \\
\text { disease (\%) }\end{array}$ & $\begin{array}{c}\text { Odds ratio } \\
\text { (95\% confidence interval) }\end{array}$ & P-value ${ }^{\star}$ & P-value ${ }^{\dagger}$ \\
\hline Age (y) & & & & $<0.001$ & $<0.001$ \\
\hline $20-49$ & 7,803 & $206(2.6)$ & 1.000 & & \\
\hline $50-59$ & 5,245 & $204(3.7)$ & 1.473 & $<0.001$ & \\
\hline $60-69$ & 3,813 & $228(5.6)$ & 2.265 & $<0.001$ & \\
\hline$\geq 70$ & 3,081 & $183(5.6)$ & 2.250 & $<0.001$ & \\
\hline Sex & & & & 0.338 & 0.178 \\
\hline Male & 11,066 & $451(4.1)$ & 1.000 & & \\
\hline Female & 9,697 & $370(3.8)$ & $0.842(0.711-1.074)$ & & \\
\hline Birthplace & & & & 0.048 & 0.047 \\
\hline Jeju Island natives & 16,111 & $617(3.8)$ & 1.000 & & \\
\hline Jeju Island migrants & 4,652 & $204(4.4)$ & $1.152(0.980-1.354)$ & & \\
\hline Body mass index (kg/m²) & & & & $<0.001$ & $<0.001$ \\
\hline$<18.5$ & 393 & $10(2.5)$ & 1.000 & & \\
\hline $18.5-22.9$ & 5,293 & $163(3.1)$ & $1.217(0.637-2.324)$ & 0.552 & \\
\hline $23.0-24.9$ & 4,317 & $168(3.9)$ & $1.551(0.812-2.960)$ & 0.183 & \\
\hline$\geq 25.0$ & 10,308 & $468(4.5)$ & $1.822(0.966-3.436)$ & 0.064 & \\
\hline Fasting blood glucose (mg/dL) & & & & $<0.001$ & $<0.001$ \\
\hline$<100$ & 14,645 & $508(3.5)$ & 1.000 & & \\
\hline $100-125$ & 4,459 & $208(4.7)$ & $1.362(1.155-1.606)$ & $<0.001$ & \\
\hline$\geq 126$ & 1,659 & $105(6.3)$ & $1.880(1.514-2.335)$ & $<0.001$ & \\
\hline Total cholesterol (mg/dL) & & & & 0.325 & 0.171 \\
\hline$<200$ & 11,407 & $472(4.1)$ & 1.000 & & \\
\hline $200-239$ & 6,586 & $246(3.7)$ & $0.889(0.768-1.052)$ & & \\
\hline$\geq 240$ & 2,770 & $103(3.7)$ & $0.895(0.720-1.112)$ & & \\
\hline Low-density lipoprotein cholesterol (mg/dL) & & & & 0.912 & 0.849 \\
\hline$<100$ & 5,679 & $218(3.8)$ & 1.000 & & \\
\hline $100-129$ & 7,016 & $287(4.1)$ & $1.068(0.893-1.279)$ & 0.470 & \\
\hline $130-159$ & 4,654 & $178(3.8)$ & $0.996(0.814-1.219)$ & 0.971 & \\
\hline $160-189$ & 1,600 & $67(4.2)$ & $1.095(0.828-1.448)$ & 0.525 & \\
\hline$\geq 190$ & 1,356 & $53(3.9)$ & $1.019(0.750-1.384)$ & 0.904 & \\
\hline High-density lipoprotein cholesterol (mg/dL) & & & & $<0.001$ & $<0.001$ \\
\hline$<40$ & 2,843 & $154(5.4)$ & 1.000 & 0.001 & \\
\hline $40-60$ & 10,676 & $426(4.0)$ & $0.726(0.601-0.877)$ & $<0.001$ & \\
\hline$\geq 60$ & 7,236 & $241(3.3)$ & $0.602(0.489-0.740)$ & $<0.001$ & \\
\hline Triglycerides (mg/dL) & & & & 0.990 & 0.753 \\
\hline$<150$ & 15,423 & $606(3.9)$ & 1.000 & & \\
\hline $150-199$ & 2,234 & $90(4.0)$ & $1.026(0.819-1.287)$ & 0.821 & \\
\hline $200-499$ & 2,187 & $88(4.0)$ & $1.025(0.816-1.288)$ & 0.832 & \\
\hline$\geq 500$ & 911 & $37(4.0)$ & $1.035(0.738-1.453)$ & 0.842 & \\
\hline Aspartate aminotransferase (IU/L) & & & & $<0.001$ & $<0.001$ \\
\hline$\leq 32$ for men or $\leq 26$ for women & 17,127 & $638(3.7)$ & 1.000 & & \\
\hline$>32$ for men or $>26$ for women & 3,628 & $183(5.0)$ & $1.373(1.160-1.625)$ & & \\
\hline Alanine aminotransferase (IU/L) & & & & $<0.001$ & $<0.001$ \\
\hline$\leq 34$ for men or $\leq 24$ for women & 12,264 & $420(3.4)$ & 1.000 & & \\
\hline$>34$ for men or $>24$ for women & 8,491 & $401(4.7)$ & $1.398(1.216-1.607)$ & & \\
\hline$\gamma$-glutamyl transferase (IU/L) & & & & 0.047 & 0.026 \\
\hline$\leq 71$ & 17,080 & $654(3.8)$ & 1.000 & & \\
\hline$>71$ & 3,683 & $167(4.5)$ & $1.193(1.003-1.419)$ & & \\
\hline Alkaline phosphatase (IU/L) & & & & 0.146 & 0.079 \\
\hline$\leq 130$ & 4,809 & $173(3.6)$ & 1.000 & & \\
\hline$>130$ & 15,946 & $648(4.1)$ & $1.135(0.957-1.347)$ & & \\
\hline Medication for dyslipidemia & & & & 0.210 & 0.253 \\
\hline Yes & 201 & $12(6.0)$ & $0.764(0.501-1.164)$ & & \\
\hline No & 20,562 & 809 (3.9) & 1.000 & & \\
\hline Medication for diabetes & & & & 0.144 & 0.253 \\
\hline Yes & 748 & $23(3.1)$ & $1.550(0.861-2.790)$ & & \\
\hline No & 19,217 & $798(4.0)$ & 1.000 & & \\
\hline
\end{tabular}

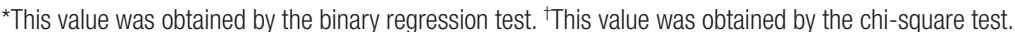




\section{Univariate Analysis of Risk Factors Affecting Gallstone Disease}

The factors affecting GD were analyzed (Table 2). The prevalence of GD for age was $2.6 \%$ in the $<50$ age group, $3.7 \%$ in the $50-59$ age group, $5.6 \%$ in the $60-69$ age group, and $5.6 \%$ in the $\geq 70$ age group. The prevalence significantly increased with age $(\mathrm{P}<0.001)$. For birthplace, the prevalence of GD was $3.8 \%$ in JNs and $4.4 \%$ in JMs, and the difference was statistically significant $(\mathrm{P}=0.047)$. The prevalence of GD was significantly associated with BMI $(\mathrm{P}<0.001)$ and fasting blood glucose levels

Table 3. Multivariate analysis of risk factors of gallstone disease in the Jeju Island people who underwent medical checkups

\begin{tabular}{|c|c|c|}
\hline Factors & $\begin{array}{l}\text { Odds ratio (95\% } \\
\text { confidence interval) }\end{array}$ & P-value* \\
\hline Age (y) & & $<0.001$ \\
\hline $20-49$ & 1 & \\
\hline $50-59$ & $1.426(1.167-1.741)$ & 0.001 \\
\hline $60-69$ & $2.191(1.798-2.670)$ & $<0.001$ \\
\hline$\geq 70$ & $2.188(1.769-2.706)$ & $<0.001$ \\
\hline Fasting blood glucose (mg/dL) & & 0.010 \\
\hline$<100$ & 1 & \\
\hline $100-125$ & $1.130(0.953-1.340)$ & 0.160 \\
\hline$\geq 126$ & $1.405(1.122-1.759)$ & 0.003 \\
\hline High-density lipoprotein cholesterol (mg/dL) & & 0.001 \\
\hline$<40$ & 1 & \\
\hline $40-60$ & $1.502(1.215-1.837)$ & $<0.001$ \\
\hline$\geq 60$ & $1.171(0.995-1.376)$ & 0.058 \\
\hline Alanine aminotransferase (IU/L) & & $<0.001$ \\
\hline$\leq 34$ for men or $\leq 24$ for women & 1 & \\
\hline$>34$ for men or $>24$ for women & $1.294(1.097-1.465)$ & \\
\hline Birthplace & & 0.008 \\
\hline Jeju Island natives & 1 & \\
\hline Jeju Island migrants & $1.248(1.059-1.471)$ & \\
\hline Sex & & 0.223 \\
\hline Male & 1 & \\
\hline Female & $0.908(0.776-1.062)$ & \\
\hline Body mass index $\left(\mathrm{kg} / \mathrm{m}^{2}\right)$ & & 0.096 \\
\hline$<18.5$ & 1 & \\
\hline $18.5-22.9$ & $1.127(0.588-2.158)$ & 0.121 \\
\hline $23.0-24.9$ & $1.269(0.661-2.436)$ & 0.174 \\
\hline$\geq 25.0$ & $1.428(0.751-2.714)$ & 0.074 \\
\hline Alkaline phosphatase (IU/L) & & 0.500 \\
\hline$\leq 130$ & 1 & \\
\hline$>130$ & $1.066(0.838-1.233)$ & \\
\hline Aspartate aminotransferase (IU/L) & & 0.291 \\
\hline$\leq 32$ for men or $\leq 26$ for women & 1 & \\
\hline$>32$ for men or $>26$ for women & $1.110(0.908-1.357)$ & \\
\hline$\gamma$-glutamyl transferase & & 0.993 \\
\hline$\leq 71$ & 1 & \\
\hline$>71$ & $1.017(0.838-1.233)$ & \\
\hline Medication for diabetes & & 0.795 \\
\hline Yes & $1.104(0.605-2.014)$ & \\
\hline No & 1 & \\
\hline Medication for dyslipidemia & & 0.211 \\
\hline Yes & $0.764(0.500-1.167)$ & \\
\hline No & 1 & \\
\hline
\end{tabular}

${ }^{*}$ Analyzed by binary logistic regression.
$(\mathrm{P}<0.001)$.

The prevalence of GD in the Jeju Island people was significantly associated with low HDL cholesterol, but not with the total cholesterol, LDL cholesterol, or triglyceride levels. The prevalence of GD was significantly higher in male subjects with AST $>32$ IU/L and in female subjects with AST $>26$ IU/L $(\mathrm{P}<0.001)$ and in male subjects with and female subjects with ALT $>34 \mathrm{IU} / \mathrm{L}$ and $>24 \mathrm{IU} / \mathrm{L}(\mathrm{P}<0.001)$, respectively. The prevalence of GD was significantly higher in subjects with $\gamma$ GTP > 71 IU/L (P=0.026), but differences in ALP were not statistically significant.

\section{Multivariate Analysis of Risk Factors Affecting Gallstone Disease}

Binary logistic regression analysis was performed for variables, including age, birthplace, BMI, fasting blood glucose, HDL cholesterol, AST, ALT, and $\gamma$-GTP, to identify risk factors affecting GD (Table 3). The independent risk factors identified to affect GD were older age, higher fasting blood glucose levels, lower HDL cholesterol and higher ALT levels, and JNs. The prevalence of GD significantly increased with age (odds ratio [OR], 1.426 in the 50-59 age groups; OR, 2.191 in the 60-69 age groups; and $\mathrm{OR}, 2.188$ in the $\geq 70$ age groups; $\mathrm{P}<0.001$ for all) and in subjects with high fasting blood glucose level of $\geq 126 \mathrm{mg} / \mathrm{dL}$ (OR, 1.405; $\mathrm{P}=0.003)$. The independent risk factors were HDL-cholesterol levels between 40 and $60 \mathrm{mg} / \mathrm{dL}$ (OR, 1.502; $\mathrm{P}<0.001$ ), ALT $>34 \mathrm{IU} / \mathrm{L}$ for men, ALT >24 IU/L for women (OR, 1.294; $\mathrm{P}<0.001)$, and JMs (OR, 1.248; $\mathrm{P}=0.008)$.

Table 4. Comparison between Jeju Island natives and Jeju Island migrants according to their birthplace in the Jeju Island people who underwent medical checkups

\begin{tabular}{lccr}
\hline \multicolumn{1}{c}{ Variable } & $\begin{array}{c}\text { Natives } \\
(\mathrm{n}=16,111)\end{array}$ & $\begin{array}{c}\text { Migrants } \\
(\mathrm{n}=4,652)\end{array}$ & P-value \\
\hline Sex & & & 0.827 \\
$\quad$ Male & $8,587(53.3)$ & $2,479(53.3)$ & \\
$\quad$ Female & $7,524(46.7)$ & $2,173(46.7)$ & \\
Gallstone disease & & & 0.047 \\
$\quad$ Yes & $617(3.8)$ & $204(4.4)$ & \\
$\quad$ No & $15,494(96.2)$ & $4,448(95.6)$ & \\
Age (y) & $55.4 \pm 13.7$ & $52.2 \pm 12.2$ & $<0.001$ \\
Body mass index (kg/m²) & $24.6 \pm 3.3$ & $24.0 \pm 3.4$ & $<0.001$ \\
Fasting blood glucose (mg/dL) & $98.1 \pm 25.1$ & $96.8 \pm 23.2$ & 0.002 \\
Total cholesterol (mg/dL) & $196.7 \pm 37.3$ & $194.4 \pm 36.7$ & $<0.001$ \\
Low-density lipoprotein cholesterol & $119.6 \pm 33.8$ & $115.7 \pm 33.0$ & $<0.001$ \\
$\quad$ (mg/dL) & & & \\
High density lipoprotein cholesterol & $54.4 \pm 13.6$ & $54.7 \pm 13.7$ & 0.222 \\
$\quad$ (mg/dL) & & & \\
Triglyceride (mg/dL) & $116.3 \pm 83.2$ & $121.3 \pm 89.3$ & $<0.001$ \\
Aspartate aminotransferase (IU/L) & $28.7 \pm 32.4$ & $26.5 \pm 21.5$ & $<0.001$ \\
Alanine aminotransferase (IU/L) & $31.4 \pm 43.7$ & $29.0 \pm 33.3$ & 0.001 \\
$\begin{array}{l}\gamma \text {-glutamyl transferase (IU/L) } \\
\text { Alkaline phosphatase (IU/L) }\end{array}$ & $45.7 \pm 69.0$ & $42.1 \pm 62.5$ & 0.002 \\
\hline
\end{tabular}

Values are presented as number (\%) or mean \pm standard deviation. 


\section{Comparison of Clinical Variables between Jeju Island Natives and Migrants}

Subjects were divided into two groups (JNs and JMs) according to their birthplace and analyzed to investigate differences between the groups (Table 4). JNs were significantly older than JMs and showed significantly higher BMI, fasting blood glucose, total cholesterol, LDL cholesterol, AST, ALT, $\gamma$-GTP, and ALP levels. Interestingly, the triglyceride levels were significantly lower in JNs $(\mathrm{P}<0.001)$.

\section{Comparison of Clinical Variables between Jeju Island Natives and Migrants in the 60-69-Year Age Group}

Subjects aged 60-69 years were subdivided into two groups (JNs versus JMs) according to their birthplace and analyzed to investigate the differences between the two groups in order to determine why the prevalence of GD in this age group was significantly different (Table 5). JNs were significantly older and showed significantly higher BMI, LDL cholesterol and lower triglyceride levels than JMs, while fasting blood glucose, total cholesterol, AST, ALT, $\gamma$-GTP, and ALP levels were comparable.

\section{Comparison of Alcohol Consumption between Jeju Island Natives and Migrants}

Of the 20,763 subjects, 4,386 subjects were selected based on data available on alcohol consumption from healthcare questionnaires. We compared the percentage of high-risk alcohol drinkers among JNs and JMs. The percentages of high-risk alcohol drinkers in JNs $(n=3,298)$ and in JMs $(\mathrm{n}=1,088)$ were $22.6 \%$ and $19.5 \%$, respectively. The percentage of high-risk alcohol consumption in JNs was significantly higher

Table 5. Comparison between Jeju Island natives and Jeju Island migrants according to their birthplace among individuals from the Jeju Island people in their 60s who underwent medical checkups

\begin{tabular}{lccc}
\hline \multicolumn{1}{c}{ Variable } & $\begin{array}{c}\text { Natives } \\
(\mathrm{n}=3,119)\end{array}$ & $\begin{array}{c}\text { Migrants } \\
(\mathrm{n}=922)\end{array}$ & P-value \\
\hline Sex (\%) & & & 0.072 \\
$\quad$ Male & $1,611(51.7)$ & $455(48.3)$ & \\
$\quad$ Female & $1,508(48.3)$ & $477(51.7)$ & \\
Gallstone disease & & & 0.028 \\
$\quad$ Yes & $162(5.2)$ & $66(7.2)$ & \\
$\quad$ No & $2,957(94.8)$ & $856(92.8)$ & \\
Age (y) & $64.4 \pm 3.0$ & $63.8 \pm 2.9$ & $<0.001$ \\
Body mass index (kg/m²) & $25.0 \pm 3.0$ & $24.7 \pm 3.0$ & 0.023 \\
Fasting blood glucose (mg/dL) & $103.0 \pm 27.7$ & $103.3 \pm 26.7$ & 0.829 \\
Total cholesterol (mg/dL) & $202.5 \pm 37.3$ & $200.7 \pm 37.9$ & 0.202 \\
Low-density lipoprotein cholesterol & $124.9 \pm 34.0$ & $121.2 \pm 34.8$ & 0.005 \\
$\quad$ (mg/dL) & & & \\
High-density lipoprotein cholesterol & $54.5 \pm 13.6$ & $54.9 \pm 14.0$ & 0.375 \\
$\quad$ (mg/dL) & & & \\
Triglyceride (mg/dL) & $117.1 \pm 72.8$ & $124.0 \pm 82.4$ & 0.017 \\
Aspartate aminotransferase (IU/L) & $30.7 \pm 36.7$ & $28.7 \pm 22.2$ & 0.118 \\
Alanine aminotransferase (IU/L) & $31.6 \pm 41.1$ & $29.7 \pm 32.6$ & 0.181 \\
\hline $\begin{array}{l}\gamma \text {-glutamyl transferase (IU/L) } \\
\text { Alkaline phosphatase (IU/L) }\end{array}$ & $46.0 \pm 72.2$ & $45.3 \pm 70.2$ & 0.803 \\
\hline
\end{tabular}

Values are presented as number (\%) or mean \pm standard deviation. than in JMs $(\mathrm{P}=0.034)$. The percentage of high risk alcohol consumption in JNs $(n=2,582)$ and in JMs $(n=841)$ in the subgroup aged $<60$ years was $25.1 \%$ and $21.3 \%$, respectively $(\mathrm{P}=0.026)$. The percentage of high-risk alcohol consumption in JNs and JMs in the subgroup aged $\geq 60$ years was $13.7 \%$ and $13.4 \%$, respectively $(\mathrm{P}=1.000$ ).

\section{DISCUSSION}

The prevalence of GD has been reported to range from $10 \%$ to $20 \%$ in Western adults and is 2 or 3 times higher in women. ${ }^{1,6)}$ However, GD has also been reported in $2 \%$ to $6 \%$ of Eastern populations, with is no statistically significant difference among sexes, with women having a slightly higher incidence than men. The prevalence of GD in this study showed no significant difference between men (4.1\%) and women (3.8\%), which was consistent with the results of previous studies. ${ }^{15-17)}$ The prevalence of GD in mainland people with medical checkups has been reported to be between $2 \%$ and $3 \%,{ }^{15,18)}$ which is relatively lower than that found in our study (4.0\%). Western foods with higher caloric content and refined carbohydrates are known risk factors for GD. ${ }^{19)}$ As many Koreans have consumed Western food (high calories and refined carbohydrates), it is estimated that the prevalence of GD has increased not only in the mainland people but also in the Jeju Island people. We determined whether such changes in Korean eating habits might have affected the prevalence of GD; however, no significant trend was found over this time period. However, it may be considered that a time span of 13 years (2003-2015) may be relatively short to have an impact on the development of GD.

It has been demonstrated that both cholesterol and pigment stones increase. ${ }^{15,16,18,20)}$ In our study, the prevalence of GD in the Jeju Island people increased with age. Einarsson et al. ${ }^{21)}$ reported that the cholesterol saturation of bile increased with age as a consequence of enhanced hepatic secretion of cholesterol and decreased bile acid synthesis. The progressive change in the ratio between bile acid synthesis and cholesterol saturation causes supersaturation of cholesterol. This could explain why the prevalence of GD increases with age. In the present study, age was also a strong and independent risk factor. However, only subjects in their 60s showed significant differences in the prevalence of GD between JNs and JMs. Similarly to other age groups, JNs had significantly higher LDL cholesterol, BMI, were of older age, and had lower triglyceride levels than JMs in this age group. However, the factors associated with alcohol consumption such as AST, ALT, and $\gamma$-GTP levels were comparable. The percentage of high-risk alcohol drinkers among JNs and JMs in this age group was not significantly different, which was consistent with the laboratory results. Dietary factors such as triglyceride and LDL cholesterol levels, and age might make the prevalence of GD in this age group significantly different. In other words, compared to other age groups, consuming alcohol had less of an impact on the development of GD than age and dietary factors. Further studies are needed in order to confirm our findings.

Previous studies reported hyperinsulinemia and insulin resistance as risk factors of GD. ${ }^{22,23)}$ Our study found that higher fasting blood glu- 
cose was an independent risk factor affecting GD. Subjects who had a fasting glucose level of $126 \mathrm{mg} / \mathrm{dL}$ or more were clinically suspected of diabetes; therefore, they could have a higher possibility of hyperinsulinemia or insulin resistance. Hyperinsulinemia or insulin resistance could strongly affect GD because the insulin level was related to biliary cholesterol saturation. In other words, insulin plays a significant role in fortifying the activity of hydroxyl-3-methylglutaryl-coenzyme A reductase, a rate-limiting step in the synthesis of cholesterol. ${ }^{24)}$ Therefore, the higher the insulin level, the more the cholesterol synthesis occurs, which causes cholesterol supersaturation. These findings could also explain why the prevalence of GD increases with increasing levels of fasting glucose.

Yang and Hwang ${ }^{25)}$ reported that mixed grains of millet, Sawa millet, and barley are staple foods of the Jeju Island people because Jeju Island has different agricultural habits due to the different types of soils and environments. It is impossible to accomplish rice paddy farming in this island. Moreover, the Household Per Capita Food Grain Consumption Survey of 2009 showed that the Jeju Island people consumed $64.1 \mathrm{~kg}$ of rice per person, which was lower than the Korean average of $70.0 \mathrm{~kg}$ and lower compared to other regions. ${ }^{26)}$ For these reasons, JNs appear to consume fewer carbohydrates than JMs. Our study also indicated that triglyceride levels were higher in JMs than in JNs. This is strong evidence suggesting that JNs consume fewer carbohydrates. Mathur et al. ${ }^{27)}$ have shown that higher carbohydrate consumption alters biliary motility and enhances crystal formation. Carbohydrates play an important role in the development of cholesterol GD. It is conceivable that the prevalence of GD is higher in JMs compared to JNs because JMs consume more carbohydrates than JNs. The present study demonstrated that the prevalence of GD in JNs was significantly lower compared to JMs, even though JNs had higher BMIs, fasting blood glucose, and LDL cholesterol levels, which are known risk factors affecting GD. This discrepancy suggested that JNs might have sufficiently strong protective factors to influence risk factors affecting GD. The reduced intake of carbohydrates in the JNs diet might represent a protective factor.

Scragg et al. ${ }^{7)}$ documented that the moderate consumption of alcohol $(39 \mathrm{~g} / \mathrm{d})$ is a protective factor for the development of GD. A moderate consumption of alcohol is associated with a decreased cholesterol saturation index, ${ }^{28)}$ which is probably due to the enhanced conversion of cholesterol to bile acids. ${ }^{29)}$ In addition, alcohol consumption is related to increased whole-gut transit time. ${ }^{30)}$ Gallstone formation is favored by decreased intestinal transit time due to the increased colonic absorption of deoxycholic acid. ${ }^{2)}$ Our study showed that JNs had a higher percentage of high-risk alcohol drinkers and higher levels of AST, ALT, ALP, and $\gamma$-GTP relative to chronic alcohol consumption than JMs. These findings can provide strong evidence for chronic alcohol consumption in JNs. Thus, chronic alcohol consumption in JNs might be another protective factor.

The present study has some limitations. First, the birthplace was analyzed instead of the period of residence, which may have provided more information, as we did not survey the subjects directly. However, moving between the island and the mainland was not easy before 2000 , as various modes of transport including low-cost carriers and fast ferries were not available and there were not enough jobs for people to move to the Jeju Island with their families at that time. Subjects who aged over 20 years might have lived on the mainland or on the island for a long time without migrating. They would thus have been sufficiently influenced by the dietary habits and environment of their birthplace; therefore, it is reasonable to classify subjects into JNs and JMs according to their birthplace. Secondly, this study was a retrospective design, since was analyzed subjects who underwent medical checkups at the Health Promotion Center of Jeju National University Hospital. However, our hospital is the only university hospital on the Jeju Island. Moreover, most of the Jeju Island inhabitants visit our hospital for medical checkups, and our hospital has sufficient medical records. For this reason, it is thought that this study would reflect the overall results of the Jeju Island people. Third, factors associated with GD, such as viral hepatitis, socioeconomic status (income and education), residence period, dietary habit, exercise and weight change were not collected and analyzed in this study. Fourthly, the subjects could not be analyzed according to the type of gallstone (pigment or cholesterol stones), which was not included in the medical records of the subjects. Finally, if the analysis was performed according to sex, the results may differ from those of the current study because there may be biological differences between males and females. However, we did not analyze the risk factors for GD according to sex because the sex factor was not statistically significant. Even though this study has some limitations, it is meaningful as this is the first study on the incidence of GD in the Jeju Island people, indicating that the prevalence of GD in JNs is low compared to JMs. Further long-term prospective studies are required in order to confirm our results.

In conclusion, the prevalence of GD was significantly lower in JNs than in JMs. Older age, JMs, higher fasting blood glucose and ALT levels, and lower HDL cholesterol levels may affect the prevalence of GD in Jeju Island. The results of this study suggest that JNs may have protective factors against GD, such as a high chronic alcohol consumption and a low carbohydrate intake.

\section{CONFLICT OF INTEREST}

No potential conflict of interest relevant to this article was reported.

\section{ACKNOWLEDGMENTS}

This work was supported by a research grant from the Jeju National University Hospital (2015-35).

\section{REFERENCES}

1. Jorgensen T, Kay L, Schultz-Larsen K. The epidemiology of gallstones in a 70 -year-old Danish population. Scand J Gastroenterol 1990;25:335-40. 
2. Shoda J, He BF, Tanaka N, Matsuzaki Y, Osuga T, Yamamori S, et al. Increase of deoxycholate in supersaturated bile of patients with cholesterol gallstone disease and its correlation with de novo syntheses of cholesterol and bile acids in liver, gallbladder emptying, and small intestinal transit. Hepatology 1995;21:1291-302.

3. Angelico F, Del Ben M, Barbato A, Conti R, Urbinati G. Ten-year incidence and natural history of gallstone disease in a rural population of women in central Italy. The Rome Group for the Epidemiology and Prevention of Cholelithiasis (GREPCO). Ital J Gastroenterol Hepatol 1997;29:249-54.

4. Barbara L, Sama C, Morselli Labate AM, Taroni F, Rusticali AG, Festi D, et al. A population study on the prevalence of gallstone disease: the Sirmione Study. Hepatology 1987;7:913-7.

5. Berger MY, van der Velden JJ, Lijmer JG, de Kort H, Prins A, Bohnen AM. Abdominal symptoms: do they predict gallstones?: a systematic review. Scand J Gastroenterol 2000;35:70-6.

6. Jorgensen T. Prevalence of gallstones in a Danish population. Am J Epidemiol 1987;126:912-21.

7. Scragg RK, McMichael AJ, Baghurst PA. Diet, alcohol, and relative weight in gall stone disease: a case-control study. Br Med J (Clin Res Ed) 1984;288:1113-9.

8. Maclure KM, Hayes KC, Colditz GA, Stampfer MJ, Speizer FE, Willett WC. Weight, diet, and the risk of symptomatic gallstones in middleaged women. N Engl J Med 1989;321:563-9.

9. Korean Association for the Study of the Liver. White paper on liver disease Korea 2013. Seoul: Jin Press; 2014.

10. Cooperberg PL, Burhenne HJ. Real-time ultrasonography: diagnostic technique of choice in calculous gallbladder disease. N Engl J Med 1980;302:1277-9.

11. WHO Expert Consultation. Appropriate body-mass index for Asian populations and its implications for policy and intervention strategies. Lancet 2004;363:157-63.

12. American Diabetes Association. (2) Classification and diagnosis of diabetes. Diabetes Care 2015;38 Suppl:S8-S16.

13. Committee for Guidelines for Management of Dyslipidemia. 2015 Korean guidelines for management of dyslipidemia. J Lipid Atheroscler 2015;4:61-92.

14. Sohn W, Jun DW, Kwak MJ, Park Q, Lee KN, Lee HL, et al. Upper limit of normal serum alanine and aspartate aminotransferase levels in Korea. J Gastroenterol Hepatol 2013;28:522-9.

15. Lee JK, Rhee PL, Lee JH, Lee KT, Choi SH, Noh JH, et al. Prevalence and risk factors of gallstone in health screening people. Korean J Gastroenterol 1997;29:85-92.
16. Yi SY, Lee SK, Kim JW, Han DS, Kim MH, Min YI, et al. Clinical study on gallstone prevalence in general health screening people. Korean J Med 1994;47:352-8.

17. Hwang SW, Ou SW, Lee HJ, Lim SY, Yang JH, Cho BL, et al. Associated factor of prevalence of asymptomatic gallstone. J Korean Acad Fam Med 2001;22:1596-602.

18. Chung YJ, Park YD, Lee HC, Cho HJ, Park KS, Seo EH, et al. Prevalence and risk factors of gallstones in a general health screened population. Korean J Med 2007;72:480-90.

19. Misciagna G, Centonze S, Leoci C, Guerra V, Cisternino AM, Ceo R, et al. Diet, physical activity, and gallstones: a population-based, casecontrol study in southern Italy. Am J Clin Nutr 1999;69:120-6.

20. Acalovschi M. Cholesterol gallstones: from epidemiology to prevention. Postgrad Med J 2001;77:221-9.

21. Einarsson K, Nilsell K, Leijd B, Angelin B. Influence of age on secretion of cholesterol and synthesis of bile acids by the liver. N Engl J Med 1985;313:277-82.

22. Diehl AK. Cholelithiasis and the insulin resistance syndrome. Hepatology 2000;31:528-30.

23. Ruhl CE, Everhart JE. Association of diabetes, serum insulin, and Cpeptide with gallbladder disease. Hepatology 2000;31:299-303.

24. Nepokroeff CM, Lakshmanan MR, Ness GC, Dugan RE, Porter JW. Regulation of the diurnal rhythm of rat liver beta-hydroxy-beta-methylglutaryl coenzmye A reductase activity by insulin, glucagon, cyclic AMP and hydrocortisone. Arch Biochem Biophys 1974;160:387-96.

25. Yang LS, Hwang CS. A study on college student's understanding and preference of native foods in Cheju-do, Korea. Korean J Diet Cult 1990;5:317-30.

26. Statistics Korea. Household per capita food grain consumption in 2009 [Internet]. Daejeon: Statistics Korea; 2010 [cited 2016 Jan 8]. Available from: http://kostat.go.kr/portal/eng/pressReleases/1/index. board?bmode=read\&aSeq=272352.

27. Mathur A, Megan M, Al-Azzawi HH, Lu D, Swartz-Basile DA, Nakeeb A, et al. High dietary carbohydrates decrease gallbladder volume and enhance cholesterol crystal formation. Surgery 2007;141:654-9.

28. Thornton J, Symes C, Heaton K. Moderate alcohol intake reduces bile cholesterol saturation and raises HDL cholesterol. Lancet 1983;2:81922.

29. Nestel PJ, Simons LA, Homma Y. Effects of ethanol on bile acid and cholesterol metabolism. Am J Clin Nutr 1976;29:1007-15.

30. Probert CS, Emmett PM, Heaton KW. Some determinants of wholegut transit time: a population-based study. QJM 1995;88:311-5. 